\title{
Developing the Therapeutic Relationship Assessment Tool of Nursing Students in the Northeastern Region of Thailand
}

\author{
Somjittra Nawa ${ }^{1}$, Pattananusorn Stabhonwong ${ }^{1} \&$ Kanchana Chaipan $^{2}$ \\ ${ }^{1}$ Psychology and Guidance branch, Faculty of Education, Mahasarakham University, Thailand \\ ${ }^{2}$ Educational Psychology, Faculty of Education, Khonkaen University, Thailand \\ Correspondence: Somjittra Nawa, Faculty of Education, Mahasarakham University,Talaad subdistric, \\ Muang,Mahasarakham,44000, Thailand. Tel: 66-91-862-0041.E-mail: Nawa375@gmail.com
}

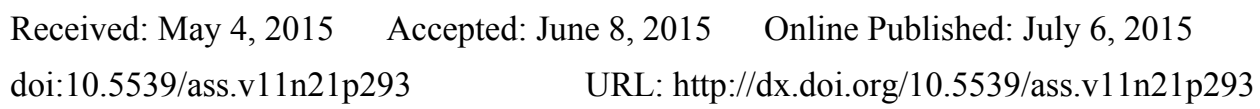

\begin{abstract}
The research aims at confirming factors, investigating sub-factors of the therapeutic relationships of nursing students, and developing the therapeutic relationship assessment tool. The samples were 400 nursing students in the Northeastern region of Thailand. The LISREL8.72 model was employed for data analysis. The research findings showed that the therapeutic relationship assessment tool consisted of five key factors with 16 sub-factors, and the 57-item-assessment tool with a 0.95 reliability index was assessed by the experts and confirmed by the empirical data. Therefore, the therapeutic relationship assessment tool is practical and appropriate for nursing students.
\end{abstract}

Keywords: therapeutic relationship, nursing student, assessment tool, development

\section{Introduction}

In Thailand, the mental patients have increased gradually approximate 1.4 million. The Ministry of Health stated that more 9 million people in Thailand had mental health problems in 2013. However, only 1.7 million patients were treated well (Office of the National Social Economic Development (2014). Chanokreuthai Chuenarom (2009) states that Psychiatrist plays an important role in taking care of the mental health patients which the mental health treatment is different from the physical treatment of the patients. The patient himself is a major person for the efficient treatment. It is necessary to establish the relationships between patients and psychiatrists focusing on awareness of the problems and need of the patients for both physical and mental treatment. Peplau, (1952) described nursing as...A significant, therapeutic, interpersonal process. It functions co-operatively with other human processes that make health possible for individuals in communities. An educative instrument, a maturing force that aims to promote forward movement of personality in the direction of creative, constructive, productive, personal, and community living.

The literature review shows that nursing students have encountered the problems of building nurse-client relationship. Panthila Itharat (2000) states that most of nursing students have been afraid of being hurt by the mental health patients, and they really worried about slow response and communication with the patients. Suwimol Jodpimai, Thaweewan Buphatha and Cholthicha Cholsawat (2011) claim that most of nursing students had problem of theoretical application to practice, and they have not got any field experience in mental health treatment. They had problems of communication with the patients, and they also could not identify physical problems of the patients.

The therapeutic relationship assessment is an important method for the treatment of mental health problems. Sawitri Yeanbuasri (1997) constructed the relationship assessment tool for the treatment of nursing students, and ability assessment form for the solution of relationships. Patara-ampai Pipatnanon and Ampaipan Pumsrisawat (1996) assessed the relationship of nursing students for the treatment by observing and recording techniques. Spreng et al. (2009) studied on the client care in Toronto, Canada, developed the assessment and validity of the factors in client care assessment. However, the study did not cover relationship assessment for the treatment of the mental health patients. Mcguire - Snieckus et al. (2007) studies the new relationship assessment model for the treatment of mental health patients in local mental health treatment centers by using psychological principles and a test. 
According to the previous research, it is obvious that there have been a few studies on relationship assessment for the treatment of the mental health problems. The author conducted research on confirming factors, investigating sub-factors of the therapeutic relationships of nursing students constructing and developing the therapeutic relationship assessment tool of nursing students.

\section{Method}

Phase 1: Confirming factors and investigating sub-factors in the therapeutic relationships

The author studied theories and research on definitions and factors in the therapeutic relationships. The focus group technique for five experts was employed for designing a conceptual framework. The guidelines for the therapeutic relationship factors of College of Nurse of Ontario revised (2006) and investigating sub-factors in the therapeutic relationships. The outcomes of phase 1 were five key factors major with 16 sub-factors. The focus group activities took two hours. The results of focus group and literature review were analyzed and synthesized for key factors and sub-factors in the therapeutic relationship assessment tool.

Phase 2: Developing the therapeutic relationship assessment tool

The therapeutic relationship assessment tool was a five rating scale assessment form with 78 items consisting of 56 inductive questions and 22 deductive questions adopted from Likert, Boonchom Srisa-ard (2002). The content validity and the index of Item Objective Congruence; IOC) was assessed by five experts. The IOC index of the assessment form was .50-1.00. The outcomes of phase 2 was a qualified 75 -item assessment tool.

Phase 3: Trying out of the assessment tool

The assessment tool was tried out to 60 nursing students. Pearson's Correlation Coefficient was employed for the discrimination analysis. The reliable index of corrected item-total correlation was .20-1.00. The internal consistency was assessed by Cronbach method Suchira Patrayutawat (2002).

Phrase 4: Confirming key factors in the therapeutic relationships

The assessment tool was implemented to 2,665 sample subjects consisting of $2^{\text {nd }}, 3^{\text {rd }}$, and $4^{\text {th }}$ year nursing students from 11 higher education institutions in the northeast of Thailand under Office of the Higher Education Commission, the Ministry of Education in 2013. They were selected by the simple random sampling method from four universities in the northeast of Thailand. The LISREL 8.72 model was employed for confirmatory factor analysis of the assessment tool Joreskog; \& Sorbom (1992).

The summary of conceptual framework are presented in the Figure 1.

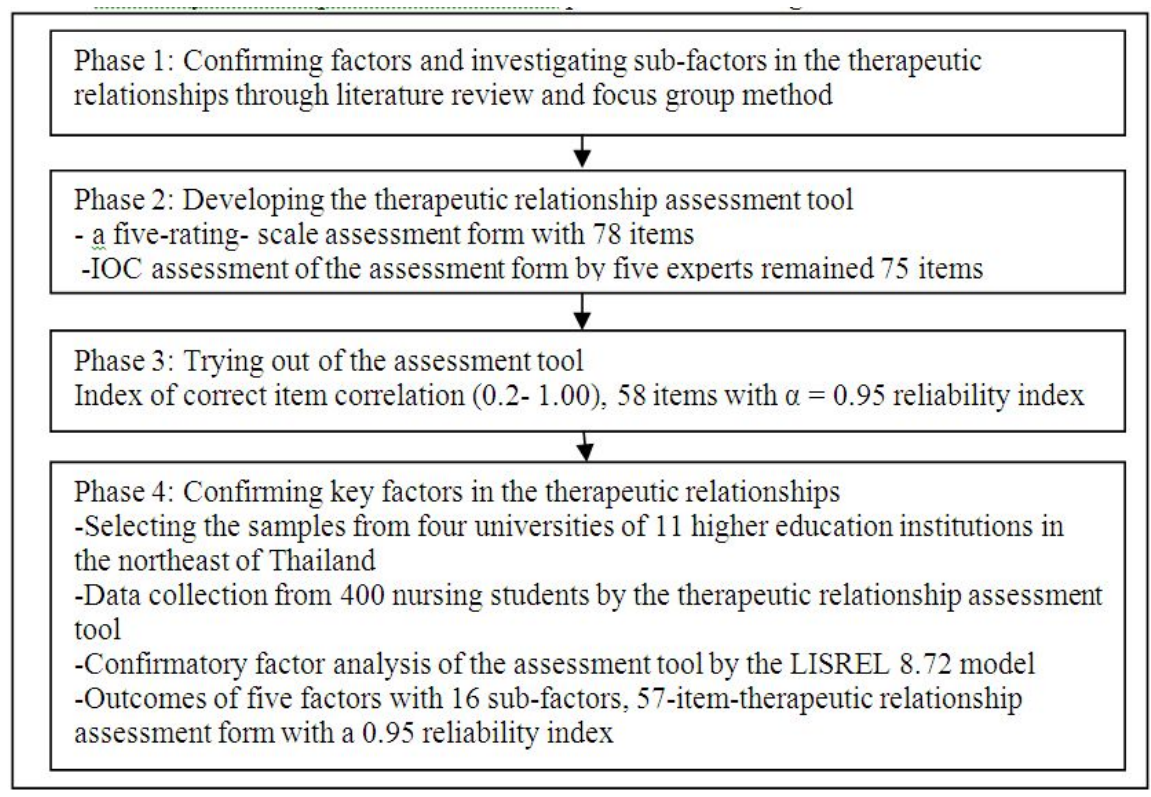

Figure 1. Summary of research framework

\section{Results}

Phase 1: Confirming key factors and investigating sub-factors in the therapeutic relationships 
The guidelines for the therapeutic relationship factors of College of Nurse of Ontario revised (2006), literature review and assessment of the experts were used to confirm the key factors and investigating sub-factors in the therapeutic relationship. The five factors with 16 sub-factors are presented in the Figure 2.

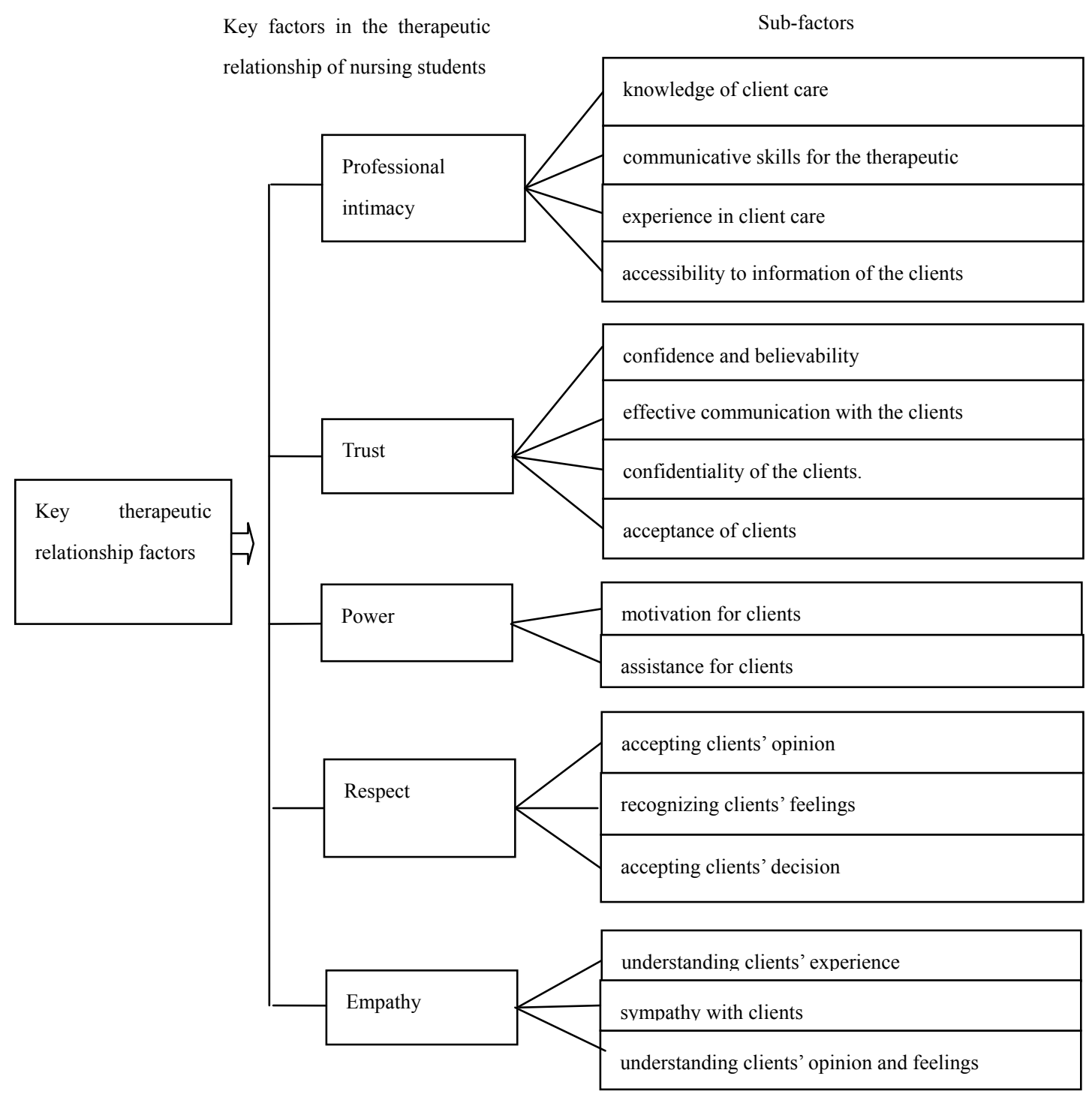

Figure 2. Five key relationship factors and sub-factors in the therapeutic relationship of nursing students

Phase 2: Developing the therapeutic relationship assessment tool

78 questions were constructed and the IOC index of the therapeutic relationship assessment tool was assessed by the experts. After that 75 questions were selected accordance with the reliable IOC index (.5-1.00).

Phase 3: Trying out of the assessment tool

The questions were tried out to 60 nursing students for assessing and developing the therapeutic relationship assessment tool, and 58 questions were selected accordance with the reliable index of the corrected item-total correlation $(.20-1.00)$ with a .95 reliability index of Cronbach.

Phase 4: Confirming key factors in the therapeutic relationships

The results of confirmatory factor analysis of the therapeutic relationship assessment tool are presented as follows:

The index of correlation coefficient analysis of the sub-factors in the therapeutic relationship assessment tool of nursing students is shown in Table 1. 
Table 1. Index of correlation coefficient of the sub-factors in the therapeutic relationship assessment tool of nursing students

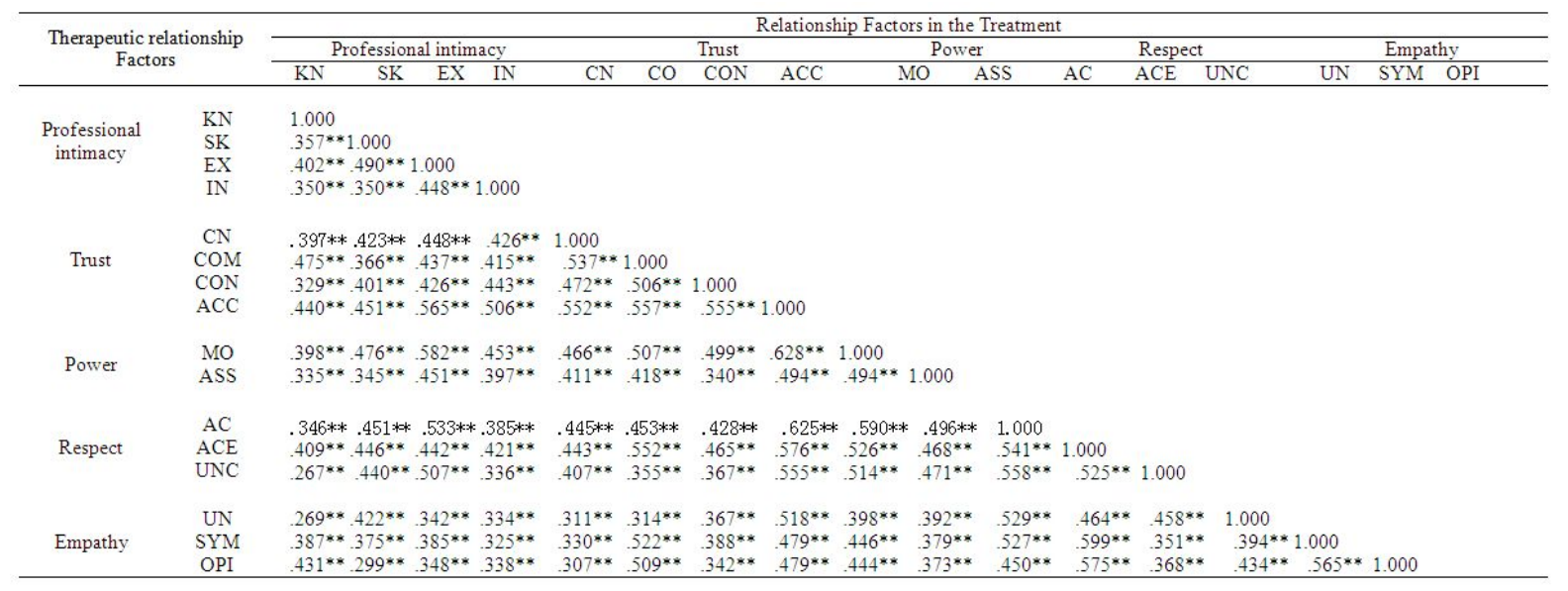

$* * \mathrm{p}<.01$

The results indicated that 16 sub-factors were positively related to each other at the .01 level of the statistical significance. The highest index of the sub-factors was motivation for clients and accepting clients (.628). Whereas, the lowest index of the sub-factors was understanding of the clients' experience and communicative skills for the treatment (.267).

The results of the confirmatory factor analysis indicated that the model was developed 18 times and 33 questions were deleted based on the LISREL 8.72 model. The therapeutic relationship assessment tool with 57 items of nursing students is showed in Table 2.

Table 2. The consistency of the therapeutic relationship assessment model with the empirical data

\begin{tabular}{|c|c|c|}
\hline & Index & Criteria \\
\hline$x^{2}$ & 103.08 & No significanc \\
\hline $\mathrm{P}$ & 0.04949 & $<.05$ \\
\hline df & 81 & - \\
\hline$x^{2} / \mathrm{df}$ & 1.27 & $<2.0$ \\
\hline Goodness of Fit Index )GFI( & 0.97 & Close to 1.0 \\
\hline Adjusted Goodness of Fit Index )AGFI ( & 0.95 & Close to 1.0 \\
\hline Comparison of Fit Index )CFI（ & 1.00 & Close to 1.0 \\
\hline Root Mean Squared Residual )RMR( & 0.011 & Close to 0.0 \\
\hline RMSEA )90\%( & 0.026 & Close to 0.0 \\
\hline
\end{tabular}

The results indicated that the average reliable level of the therapeutic relationship assessment model of nursing students was 103.08 with the .049 level of the statistical significance. Whereas, the index of relative chi-square was 1.27 without statistical significance. In conclusion, the results revealed that the overall reliable level of the assessment model was high.

Additionally, the Goodness of Fit Index was .97, the Adjusted Goodness of Fit Index was .95. The Comparison of Fit Index was 1.00. The results revealed that the model was appropriate for practical application accordance with the empirical data. Moreover, the RMSEA index was .026, which the index confirmed the appropriateness of five key factors with four sub-factors in the therapeutic relationship assessment of nursing students. The sub-factors included confidence, believability, communication with clients for facts, Confidentiality of the clients, and acceptance of clients. Two sub-factors of the power over assistance for clients consisted of empathy for clients, assistance for clients. Three sub-factors of respect for clients included accepting the opinions of clients, accepting the feelings of clients, accepting clients' decision. Three sub-factors in client care consisted of understanding of clients' experience, real sympathy on clients, accepting opinion and feelings of clients. The diagram of five key factors in the relationship assessment model is shown in Table 3. 
Table 3. Values of the second confirmatory factors assessed by the LISREL model $(n=400)$

\begin{tabular}{|c|c|c|c|c|}
\hline Therapeutic relationship factors & B & SE & t-value & $R^{2}$ \\
\hline Professional intimacy & 0.95 & 0.09 & 10.70 & 0.91 \\
\hline Trust & 0.95 & 0.07 & 13.09 & 0.90 \\
\hline Power & 1.00 & 0.06 & 17.92 & 1.01 \\
\hline Respect & 0.97 & 0.06 & 16.83 & 0.94 \\
\hline Empathy & 0.92 & 0.07 & 13.18 & 0.85 \\
\hline
\end{tabular}

Table 3. showed that the value of overall factors was positive at the .05 level of the statistical significance. The results revealed that five key factors indicated the therapeutic relationships of nursing students. Regarding each factor, the findings showed that the two highest values of the power over clients were assistance for clients was 1.00. The values of respect on clients, the professional intimacy, trust and empathy were $.97, .95, .95$ and .92 respectively. The average index of the reliability was high $\left(R^{2}\right)$. The indices of Standardized Factor Loading, Standard Error (SE), t-value and reliability are showed in Table 4.

Table 4. Indices of Standardized Factor Loading )B (, Standard Error (SE), t-value and reliability for the second confirmatory analysis $(n=400)$

\begin{tabular}{|c|c|c|c|c|}
\hline Therapeutic relationship factors & $\mathrm{B}$ & $\mathrm{SE}$ & $\mathrm{t}$ value & $\mathrm{R}^{2}$ \\
\hline \multicolumn{5}{|l|}{ Professional intimacy } \\
\hline -knowledge of client care & 0.54 & 0.03 & 9.52 & 0.29 \\
\hline -communicative skills for the treatment & 0.65 & 0.03 & 9.52 & 0.42 \\
\hline -experience in client care & 0.75 & 0.04 & 10.30 & 0.56 \\
\hline -accessibility to information of the clients & 0.60 & 0.04 & 9.09 & 0.36 \\
\hline \multicolumn{5}{|l|}{ Trust } \\
\hline -confidence and believability & 0.64 & 0.03 & 12.71 & 0.41 \\
\hline -effective communication with clients & 0.66 & 0.03 & 12.71 & 0.43 \\
\hline -confidentiality of the clients. & 0.66 & 0.05 & 11.25 & 0.43 \\
\hline -acceptance of clients & 0.85 & 0.04 & 13.60 & 0.72 \\
\hline \multicolumn{5}{|l|}{ Power } \\
\hline -motivation for clients & 0.78 & 0.03 & 12.93 & 0.60 \\
\hline -assistance of clients & 0.63 & 0.30 & 12.90 & 0.40 \\
\hline \multicolumn{5}{|l|}{ Respect } \\
\hline -accepting the opinions of clients & 0.77 & 0.03 & 14.75 & 0.59 \\
\hline - accepting the feelings of clients & 0.73 & 0.03 & 14.75 & 0.54 \\
\hline -accepting decision of clients & 0.71 & 0.03 & 14.32 & 0.51 \\
\hline \multicolumn{5}{|l|}{ Empathy } \\
\hline -understanding clients' experience & 0.68 & 0.04 & 10.33 & 0.46 \\
\hline -sympathy with clients & 0.61 & 0.04 & 10.33 & 0.38 \\
\hline - understanding clients' opinion and feelings & 0.62 & 0.03 & 10.42 & 0.38 \\
\hline
\end{tabular}

Table 4. showed the second confirmatory factor analysis of five key factors. The first factor consisted of four sub-factors: knowledge of client care, communicative skills for the treatment, experience in client care and accessibility to information of the clients. The average index of the sub-factors were .54-.75. Four sub-factors of the second factor were confidence and believability, effective communication with clients, confidentiality of the client, and accepting clients. The average index of the sub-factors were .64-.85. Two sub-factors of the third factor were motivation for clients and assistance of clients. The average index of the sub-factors were .63-.78. Three sub-factors of the fourth factor were accepting opinions, feelings and decision of clients and accepting decision of clients . The average index of the sub-factors was .71-.77. Three sub-factors of the fifth factor were understanding clients' experience, sympathy whit clients and Understanding clients' opinion and feelings. The index of the overall sub-factors was .61-68.

The index of prediction coefficient for 16 sub-factors was .29-.72. The factors consisted of accepting clients, motivation for clients, accepting the opinions of clients, experience in client care, understanding clients' opinion and feelings, accepting decision of clients, sympathy for clients, effective communication with clients, confidentiality of the clients., knowledge of client care, confidence and believability, shared goals, knowledge of client care, accepting decision for clients, understanding the opinions and feelings of clients, accessibility to clients and communicative skills for the treatment respectively. 
Table 5. Reliability index of the therapeutic relationship assessment of nursing students

\begin{tabular}{cc}
\hline Therapeutic Relationship & Reliability Index of Cronbach \\
\hline Professional intimacy & 0.78 \\
Trust & 0.84 \\
Power & 0.81 \\
Respect & 0.82 \\
Empathy & 0.85 \\
\hline
\end{tabular}

Table 5. revealed that the highest reliability indices of the five key factors in the therapeutic relationships were empathy, trust, respect, power and professional intimacy assessment were $.85, .84, .82, .81$ and .78 respectively. The overall index of the therapeutic relationship was .95.

\section{Discussion}

The focus group discussion was employed to confirm five key factors the guidelines of College of Nurse of Ontario revised 2006 (2013) and investigating in the therapeutic relationship sub-factors. The research participants of the focus group consisted of one psychiatrist doctor, two psychiatrist nursing lecturers, one psychiatrist nursing and one psychologist. The discussion took two hours and was recorded. The analysis of the focus groups found five key factors and 16 sub-factors in therapeutic relationship assessment consisted of professional intimacy, trust, power, respect and empathy. Four sub-factors in professional intimacy were knowledge of client care, communicative skills for the treatment, experience in client care and accessibility to information of the clients. College of Nurse of Ontario revised 2006 (2013) claims that nursing practitioners take an important role for client care of mental and social factors, the activities should be planned for client care. Accessibility to information and confidentiality of the clients also affect the relationship between clients and nursing practitioners. Mohr (2009) states that professionalism is the ability of nurse practitioners in applying theories to practice for building professional relationship. Four sub-factors of the second factor consisted of confidence and believability, effective communication with the clients, Confidentiality of the clients. and accepting clients. Nurse Association of New Brunswick, (2000) states that the trust of clients is important for building the relationships between clients and practitioners. Mohr (2009) states that the key factors of the trust consisted of clear communication with clients, Confidentiality of the clients., and accepting clients. Two sub-factors of the power included motivation for clients and assistance of clients. Nurse Association of New Brunswick (2000) claims that nurse practitioners have more power than clients. The power of nurses are from their job/position, and knowledge. The nurses are a major person to take care of clients with professional skills, knowledge, clear information of clients and required services. Three subfactors of the respect consisted of accepting the opinions, feelings and decision of clients. Nurse Association of New Brunswick (2000) states that the respect on each other shows status and value of human being, and the respect is necessary to establish the relationships between nurses and clients. Varcarolis et al. (2006) recommend that positive regard is important for clients, and the physical manners show more respect than verbal manners. The physical manners included of attitudes towards the service/treatment, empathy, and refusing a decision of clients. Vedebeck (2009) claims that the positive regard is identified by naming correct clients, taking time, listening to and giving quick response. Three sub-factors of the empathy consisted of understanding experience of clients, sympathy for clients and accepting the feelings of clients. Varcarolis et al. (2006) claim that empathy refers to the understanding of the opinions and feelings of clients. The empathy for clients involves communicating with clients, checking data of clients, clear understanding of the psychiatric treatment, including opinions and feeling of the clients Vedebeck (2009) defines the empathy for clients that the empathy is the attempt of understanding of ideas, meanings, feelings of clients, and the nurses are an important person to clarify their ideas and understandings.

The index of the relationship assessment tool analyzed by the LISREL 8.72 model was 103.08 . The value of the statistical significance was .04949. The index of relative chi-square was 1.27 Nonglak Wiratchai (1998). The results indicated that the IOC index of the assessment model was significantly supported by the empirical data. The Adjusted Goodness of Fit Index was .95. The Comparison Fit Index was 1.00. Supamas Ungsuphachok, Somthawill Wijitwana and Ratchaneekul Pinyopanuwat (2011) conclude that the IOC indices of the model were supported by the empirical data. The Adjusted Goodness of Fit Index and Comparison of Fit Index was .95. Root Mean Squared Residual was 0.011 and the index of RMSEA was 0.026. The IOC index of RMSEA and RMR indicated that five key factors: Professional intimacy, Trust, Power, Respect and Empathy are practical and appropriate for the therapeutic relationship assessment of nursing students.

The reliability index of the model was .95 , and the index of Internal Consistency was $0.78-0.85$ Suchira Patarayutwat. (2002) Mcguire - Snieckus (2007) developed the therapeutic relationship assessment tool of the 
experts and clients. Spreng and other (2009) states that the therapeutic relationship assessment is necessary for the treatment of nursing students.

\section{Conclusion}

The study shows that the therapeutic relationship assessment tool with 57 items consists of five key factors with 16 sub-factors. The LISREL .8.72 model was employed for confirmatory factor analysis of construct validity. The assessment model is significantly supported by the empirical data. The therapeutic relationship assessment tool was assessed by the experts and construct validity with appropriate reliability index. Therefore, the therapeutic relationship assessment tool is practical and appropriate for nursing students.

\section{References}

College of Nurses of Ontario Practice Standard. (2013). Therapeutic Nurse- Client Relationship. Revised 2006. College of Nurses of Ontario. Retrieved from http://www.cno.org/Global/docs/prac/41033_Therapeutic.pdf

Ithirat, P. (2000). The Complementary Texts for "Nursing for Mental Health Clients": Tool for the Mental Health Treatment of Nurse. The Department of Psychiatry, Faculty of Nursing khonkaen University .

Jodpimai, S., Bupatha, T., \& Cholsawat, C. (2011). The Effects of Computer Assisted Instruction on the Topic of "Establishing the relationship and Conversation for the treatment of the Mental Health Clients" on the Learning Achievement of Nursing Students. Journal of Nurses, 60(5).

Joresskog, K. G., \& Sorbom, D. (1992). LISREL VII. Analysis of Linear Structural Relations. Mooresville, IN Scientic Software.

Mcguire-Snieckus, R. (2007). A new scale to assess the therapeutic relationship in community mental health care: STAR. Psychological Medicine, 37, 85-95. Retrieved from http://webspace.qmul.ac.uk/rmccabe/ publications/2007/2007_A_new_scale_to_assess_the_therapeutic_relationship_STAR.pdf

Morh, W. K. (2009). Therapeutic Relationships and Communication in Psychiatric-Mental Health Nursing (7th ed.). China: Wolters Kluver Health.

Nurse Association of New Brunswick. (2000). Standard for the Therapeutic Nurse-Client Relationship. Nurse Association of New Brunswick. Retrieved from http://www.nanb.nb.ca/PDF/practice/Standards_for_the therapeutic_Nurse-Client_Relationship_English.pdf

Office of the National Economics and Social Development Board. (2014). Social Situation and outlook in the 3rd Quarter of 2014.

Patarayutwat, S. (2002). Guidelines for Psychological Test (1st ed.). Bangkok: The Department of Psychiatry, Faculty of medicine, Mahidol University.

Register Nurse Association of Ontario Revised 2006. (2013). Establishing therapeutic relationships. Retrieved from http://www.rnao.org

Spreng, R. N. (2009). The Toronto Empathy Questionnaire: Scale development and initial validation of a factor-analytic solution to multiple empathy measures. J. Pers. Assess., 91(1), 62-71. Retrieved from http://www.tandfonline.com/doi/full/10.1080/00223890802484381

Srisa-ard, B. (2002). Basic Research (7th ed.). Bangkok: Suviriyasarn.

Ungsuchot, S., et al. (2011). Analytical Statistics for Social Sciences and Behavioral Science Research: LISREL Program (3rd ed.). Bangkok: Charoendeemunkhong Publication Limited.

Varcarolis, M. E. et al. (2006). Foundations of Psychiatric Mental Health: A clinical approach. St Louis Saunders Company.

Vedebeck, S. L. (2009). Mental Healh Nursing. Uk: Lippincott Williams \& Wilkins.

Wiratchai, N. (1999). RISREL Model: Analytical Statistics for Research (3rd ed.). Chulalongkorn University.

Wongpanarak, N. (2014). Relationship for the Treatment: Practical Application for Nursing Process. Journal of the Thai Army Nurse, 15(2).

\section{Copyrights}

Copyright for this article is retained by the author(s), with first publication rights granted to the journal.

This is an open-access article distributed under the terms and conditions of the Creative Commons Attribution license (http://creativecommons.org/licenses/by/3.0/). 